\title{
Do Educational Supervisors Remain Open Minded to Junior Doctors?
}

\author{
Neel Sharma
}

Published online: 18 March 2014

(C) International Association of Medical Science Educators 2014

\section{Dear Editor}

Junior doctors are assigned educational supervisors from the moment they commence foundation training. Their role as the name suggests is to primarily supervise a trainee's clinical role, ensuring achievement of competencies by the end of the year.

In addition, a supervisor's role is in some form akin to a mentor, their aim also to guide trainees through the long winded hierarchy of training before reaching the end of the road. A process that takes 9 years but, in most cases, longer if undertaking research or other commitments along the way.

I, myself, have always been keen to work abroad. As I have felt that a global perspective in healthcare is essential to one's training. But was such an ideal always accepted? During my first year of core medical training (CMT), I discussed my plans to work in Asia with many a supervisor. The end result-utter dismay. I was repeatedly told that this would be in effect an end to my career. And that if I chose to leave the UK, there would be no way of reentering. Despite informing my seniors that my time in Asia will be in fact heavily career focused, it made no difference.

It was only until the end of my second year of CMT that my supervisor at the time had more insight. He was very keen on the idea and encouraged it no end. He saw the potential of my plan and was more than willing to accept it. In fact, if it was not for his influence, I probably would not have risked the move. Why was he any different you may ask? Well, it transpired that in fact he had himself worked abroad and spoke highly of such an intervention.

So despite the concept of an educational supervisor designed to provide mentorship, this I feel is somewhat lacking. Trainees should not be forced to remain bound in a box following the treadmill approach with no desire to pursue their own interests. In fact, this approach can hinder the very creativity that doctors should maintain. As long as one's additional ventures are career focused, there should be no reason why this is not looked at positively. And just because some seniors do not understand the reasons for a trainee's career choice, they should still maintain an unbiased approach.
N. Sharma $(\bowtie)$

Division of Gastroenterology and Hepatology,

National University Hospital, Singapore, Singapore

e-mail: drneelsharma@outlook.com 